\title{
Serum matrix metalloproteinase-1 level represents disease activity as opposed to fibrosis in patients with histologically proven nonalcoholic steatohepatitis
}

\author{
Wataru Ando ${ }^{1}$, Hiroaki Yokomori ${ }^{2}$, Nobuhiro Tsutsui ${ }^{3}$, Eigoro Yamanouchi ${ }^{4}$, Yutaka Suzuki ${ }^{3}$, Masaya Oda $^{5}$, \\ Yutaka Inagaki ${ }^{6,7}$, Katsuya Otori', and Isao Okazaki ${ }^{8,9}$ \\ 'Department of Clinical Pharmacy, Center for Clinical Pharmacy and Sciences, Kitasato University School of Pharmacy, Tokyo; \\ ${ }^{2}$ Department of Internal Medicine, Kitasato University Medical Center, Kitamoto; ${ }^{3}$ Department of Surgery, International University of \\ Health and Welfare Hospital, Nasu-Shiobara; ${ }^{4}$ Department of Radiology, International University of Health and Welfare Hospital, Nasu- \\ Shiobara; ${ }^{5}$ Department of Internal Medicine, Sanno Medical Center, International University of Health and Welfare, Tokyo; ${ }^{6}$ Center for \\ Matrix Biology and Medicine, Tokai University Graduate School of Medicine, Isehara; ${ }^{7}$ Department of Regenerative Medicine, Tokai \\ University School of Medicine, Isehara; ${ }^{8}$ Department of Internal Medicine, Sanno Hospital, International University of Health and \\ Welfare, Tokyo; ${ }^{9}$ Department of Internal Medicine, International University of Health and Welfare Hospital, Nasu-Shiobara, Japan
}

Background/Aims: Nonalcoholic steatohepatitis (NASH) is prevalent in both economically developed and developing countries. Twenty percent of NASH progresses to cirrhosis with/without hepatocellular carcinoma, and there is an urgent need to find biomarkers for early diagnosis and monitoring progression of the disease. Using immunohistochemical and immunoelectron microscopic examination we previously reported that expression of matrix metalloproteinase-1 (MMP1) increased in monocytes, Kupffer cells and hepatic stellate cells in early stage NASH. The present study investigated whether serum MMP-1 levels reflect disease activity and pharmaceutical effects in NASH patients.

Methods: We measured the serum levels of MMPs, tissue inhibitors of metalloproteinases (TIMPs), and several cytokines/ chemokines in patients with histologically proven early and advanced stages of NASH and compared them with those in healthy controls.

Results: Serum MMP-1 levels in stage 1 fibrosis, but not in the more advanced fibrosis stages, were significantly higher than in healthy controls $(P=0.019)$. There was no correlation between serum MMP-1 level and fibrosis stage. Serum MMP1 levels in NASH patients represented disease activity estimated by serum aminotransferase values during the followup period. In contrast, MMP-2, MMP-9 and TIMPs did not change with disease activity. Consistent with the finding that MMP-1 is expressed predominantly in monocytes and Kupffer cells, serum levels of monocyte chemotactic protein-1 and granulocyte-colony stimulating factor were significantly increased in NASH with stage 1 fibrosis.

Conclusions: These results suggest that serum MMP-1 levels represent disease activity and may serve as a potential biomarker for monitoring the progression of NASH. (Clin Mol Hepatol 2018;24:61-76)

Keywords: Nonalcoholic steatohepatitis; Matrix metalloprotease 1; Cytokines; Liver cirrhosis

\footnotetext{
Abbreviations:

ALT, alanine transaminase; AST, aspartate transaminase; BS, blood sugar; BMI, body mass index; F, fibrosis; $\gamma$-GTP, gamma-glutamyl transpeptidase; G-CSF, granulocytecolony stimulating factor; HbA1c, hemoglobin A1c; HCC, hepatocellular carcinoma; HPCs, hepatic progenitor cells; HSCs, hepatic stellate cells; HDL, high-density lipoprotein; IEM, immunoelectron microscopy; IHC, immunohistochemistry; KCs, kupffer cells; LDL, low-density lipoprotein; MCP-1, monocyte chemotactic protein-1; MCs, monocytes; MMP, matrix metalloproteinase; NAFL, nonalcoholic fatty liver; NAFLD, nonalcoholic fatty liver disease; NAS, NASH Activity Score; NASH, nonalcoholic steatohepatitis; SCF-1, stem cell factor-1; SCGF- $\beta$, stem cell growth factor- $\beta$; SDF-1a, stromal cell-derived factor 1a; TC, total cholesterol; TG, triglyceride; TIMP, tissue inhibitor of metalloproteinase
}

\section{Corresponding author: Wataru Ando}

Department of Clinical Pharmacy, Center for Clinical Pharmacy and Sciences, Kitasato University School of Pharmacy, 5-9-1 Shirokane, Minato-ku, Tokyo 108-8641, Japan

Tel: +81-3-3440-3055, Fax: +81-3-3440-3055

E-mail:andow@pharm.kitasato-u.ac.jp

http://orcid.org/0000-0001-7085-1458 


\section{INTRODUCTION}

Nonalcoholic steatohepatitis (NASH) is prevalent in both economically developed and developing countries. In Japan the number of NASH patients has been rising in recent years. ${ }^{2}$ Most patients with NASH show increased body weight due to over eating and low physical activity, and frequently present with metabolic syndrome and diabetes mellitus. ${ }^{3,4}$ Triglyceride deposits in hepatocytes cause oxidative stress in mitochondria, leading to cell death of hepatocytes and inflammation with infiltration of monocytes in the liver-6 as well as hepatocellular carcinoma with or without cirrhosis. If inflammation is not observed, the term nonalcoholic fatty liver (NAFL) is usually used in clinical practice, and the term nonalcoholic fatty liver disease (NAFLD) includes both NASH and NAFL. ${ }^{4}$

Recently we published a report on spatiotemporal expression of matrix metalloproteinase-1 (MMP-1) in histologically proven NASH liver. ${ }^{8}$ Immunohistochemical (IHC) and immunoelectron microscopic (IEM) examination revealed that monocytes (MCs), Kupffer cells (KCS) and hepatic stellate cells (HSCs) were positive for MMP1 in the early stage of NASH while hepatic progenitor cells (HPC) with MMP-1 expression appeared to transform into both bile ductules participating in ductular reaction and elongated capillary endothelial cells involving angiogenesis in the advanced stage of NASH. MMP-1 positive HPCs were observed even in the early stage of NASH. ${ }^{9}$ MMP-1 is a typical interstitial collagenase, one of the soluble-type MMPs. Moreover, MMP-1 possesses not only the unique function of breakdown of type I collagen at one quarter distance from the $\mathrm{N}$-terminal of the collagen molecule, ${ }^{10}$ but also the ability to initiate cell proliferation ${ }^{11-13}$ as well as the ability to alter cell phenotype. ${ }^{14}$

We then measured the serum levels of MMP-1 of patients with histologically proven NASH and compared them with those in

Table 1. Clinical and laboratory data of healthy controls and patients with early and advanced NASH

\begin{tabular}{|c|c|c|c|}
\hline & $\begin{array}{l}\text { Healthy controls } \\
\qquad(n=14)\end{array}$ & $\begin{array}{l}\text { Early NASH } \\
\qquad(n=24)\end{array}$ & $\begin{array}{c}\text { Advanced NASH } \\
(n=9)\end{array}$ \\
\hline Men/Women & $9 / 5$ & $18 / 6$ & $6 / 3$ \\
\hline Age (years) & $51.9 \pm 13.2$ & $46.1 \pm 9.6$ & $64.1 \pm 11.5$ \\
\hline BMI $\left(\mathrm{kg} / \mathrm{m}^{2}\right)$ & $23.2 \pm 2.95$ & $28.5 \pm 4.7^{\dagger}$ & $25.7 \pm 2.5^{\ddagger}$ \\
\hline Diabetes & 0 & $3(12.5 \%)$ & $6(66.7 \%)$ \\
\hline Metabolic syndrome & 0 & $12(50.0 \%)$ & $6(66.7 \%)$ \\
\hline AST (IU/L) & $21.0 \pm 4.3$ & $54.5 \pm 29.5^{\dagger}$ & $60.9 \pm 24.9^{\dagger}$ \\
\hline ALT (IU/L) & $18.7 \pm 5.0$ & $89.7 \pm 57.2^{\dagger}$ & $71.0 \pm 25.4^{\dagger \neq}$ \\
\hline$\gamma$-GTP (IU/L) & $23.7 \pm 10.2$ & $62.0 \pm 52.5^{\dagger}$ & $163.5 \pm 50.6^{\dagger \S}$ \\
\hline $\mathrm{TC}(\mathrm{mg} / \mathrm{dL})$ & $208.1 \pm 25.6$ & $211.0 \pm 43.6$ & $173.3 \pm 26.2^{\dagger \S}$ \\
\hline LDL (mg/dL) & $135.3 \pm 22.3$ & $132.0 \pm 32.2$ & $88.8 \pm 13.3^{* \neq}$ \\
\hline $\mathrm{HDL}(\mathrm{mg} / \mathrm{dL})$ & $55.2 \pm 16.2$ & $46.4 \pm 8.9$ & $53.5 \pm 25.4$ \\
\hline $\mathrm{TG}(\mathrm{mg} / \mathrm{dL})$ & $92.9 \pm 43.0$ & $208.6 \pm 155.2^{\dagger}$ & $135.7 \pm 79.3^{\ddagger}$ \\
\hline $\mathrm{BS}(\mathrm{mg} / \mathrm{dL})$ & $94.3 \pm 8.3$ & $113.4 \pm 44.1^{\dagger}$ & $143.8 \pm 42.5^{*}$ \\
\hline HbA1c (\%) & $5.6 \pm 0.4$ & $6.2 \pm 1.2^{\dagger}$ & $7.1 \pm 1.1^{* \neq}$ \\
\hline Plt $\left(10^{3} / \mu \mathrm{L}\right)$ & $242.6 \pm 65.5$ & $213.9 \pm 63.0$ & $141.0 \pm 37.7^{*}$ \\
\hline \multicolumn{4}{|l|}{ Histological characteristics } \\
\hline Steatosis grade $(1 / 2 / 3)$ & & $4 / 15 / 5$ & $4 / 5 / 0$ \\
\hline Ballooning grade (1/2) & & $9 / 15$ & $5 / 4$ \\
\hline Inflammation grade $(1 / 2 / 3)$ & & $11 / 11 / 2$ & $2 / 5 / 2$ \\
\hline Fibrosis stage (1/2/3/4) & & $14 / 10 / 0 / 0$ & $0 / 0 / 3 / 6$ \\
\hline
\end{tabular}

Values indicate mean \pm standard deviation (SD).

NASH, nonalcoholic steatohepatitis; BMI, body mass index; AST, aspartate aminotransferase; ALT, alanine aminotransferase; $\gamma$-GTP, gamma-glutamyl transpeptidase; TC, total cholesterol; LDL, low-density lipoprotein cholesterol; HDL, high-density lipoprotein cholesterol; TG, triglyceride; BS, blood sugar; HbA1c, hemoglobin A1c; Plt, platelet.

These values in NASH patients vs. those in healthy controls, ${ }^{*} P<0.05,{ }^{\dagger} P<0.01$; Advanced stage vs. early stage of NASH, ${ }^{\ddagger} P<0.05,{ }^{\S} P<0.01$. 
healthy controls. We measured not only MMP-1 but also other MMPs, tissue inhibitor of metalloproteases (TIMPs), stromal cellderived factor $1 \alpha$ (SDF-1 $\alpha$ ), and several cytokines to examine disease activity linked with progression to advanced stage NASH, cirrhosis and $\mathrm{HCC}^{8}$ In the present study we show that the serum level of MMP-1 is unique in reflecting the disease activity compared with the serum levels of other MMPs, their inhibitors and cytokines involved in their activation and discuss the possibility of translational research to inhibit the exosomes from KCs, MCs and HSCs, including miRNA related to MMP-1 expression as a novel target for NASH.

\section{PATIENTS AND METHODS}

\section{Patient entry and criteria for study}

This study was conducted at the Kitasato University Medical Center (Kitamoto City, Saitama, Japan) and the International University of Health and Welfare Hospital (Nasu-Shiobara City, Tochigi, Japan) between April 1, 2013 and December 31, 2016. Prior to implementation, the study protocol was approved by the ethics committee of the two institutions. All patients gave informed consent by formal letter for this study. Thirty-three histologically proven NASH patients (24 men and 9 women; mean age $50.6 \pm 12.3$ years) were entered (Table 1, Supplementary Table 1). Fourteen healthy persons ( 9 men and 5 women; mean age $51.9 \pm 13.2$ years) came to the Preventive Medical Center of the International University of Health and Welfare Hospital (Nasu-Shiobara City, Tochigi, Japan) for an annual health check and enrolled in this project.

The visitors for an annual health check underwent questionnaires (present complain, past medical history, family medical history, drinking and smoking habits, diet health conditions, physical activity, sleeping time and current drug use), a physical examination (including body weight, waist, and BMI), conventional laboratory tests including urinalysis, peripheral blood examination, clinical chemistry (blood sugar [BS] level, HbA1c, total cholesterol [TC], triglyceride [TG], high-density lipoprotein [HDL]-cholesterol, creatinine, AST, ALT, $\gamma$-GTP, CRP), stool occult blood 2 days examination, chest X-ray, electrocardiogram, upper GI endoscopy, and abdominal ultrasonography. There were 53 visitors on July 14 and 15 in 2015, among whom 14 persons showed all normal results. They were all normal ALT levels and no fatty liver on ultrasonography without diabetes, metabolic syndrome and cardiovascular diseases, and within normal range of BMI $\left(18.5-25 \mathrm{~kg} / \mathrm{m}^{2}\right)$.
The exclusion criteria for NASH patients were as follows: alcohol consumption of more than $20 \mathrm{~g} /$ day for men and more than $10 \mathrm{~g} /$ day for women; use of a hepatotoxic drug or any agent that alters cytokines, e.g., interferon; and the presence of complications, such as alcoholic steatohepatitis, chronic hepatitis B, chronic hepatitis C, primary biliary cholangitis, primary sclerosing cholangitis, chronic pancreatitis, type 1 diabetes, uncontrolled thyroid deficiency, renal failure, and need for hemodialysis, as reported previously. ${ }^{8}$

\section{Histological examination of liver biopsy, grade of fibrosis and NASH activity score (NAS)}

Tissue samples were obtained by liver biopsy and fixed for optical microscopy as reported previously. ${ }^{8}$ Conventional histological examination was performed using hematoxylin and eosin, Azan-Mallory, and silver staining. Histological evaluation was performed by optical microscopy and described according to Brunt's classification. ${ }^{15}$ Steatosis and inflammation were graded on a scale of $0-3(0$, none; 1 , mild; 2 , moderate; 3 , severe), and ballooning was graded on a scale of $0-2(0$, none; 1 , mild; 2 , moderate). Fibrosis was graded on a scale of 0-4 (0, no fibrosis; 1 , pericellular or isolated portal fibrosis: 2, combined pericellular and portal fibrosis; 3, bridging fibrosis, and 4, cirrhosis) according to the classification of Brunt. These scales were evaluated according to the NAS. ${ }^{16}$

NASH patients were classified into two groups according to Brunt's staging. ${ }^{15}$ Stages 1 and 2 were designated as early stage NASH (early NASH, $\mathrm{n}=24$ ) and stages 3 and 4 as advanced stage NASH (advanced NASH, $n=9$ ). There were 18 men and 6 women in the early NASH group and 6 men and 3 women in the advanced NASH group. The mean age of early NASH patients was younger than that of advanced NASH patients (46.1 \pm 9.6 years vs. $64.1 \pm 11.5$ years) with no statistical significance (Table 1).

The mean values of BMI, AST, ALT, $\gamma$-GTP, TG, BS, HbA1C, and platelet (PIt) in the early and advanced NASH groups were significantly different from those in healthy controls. The mean values of BMI, ALT, $\gamma$-GTP, TC, low-density lipoprotein (LDL)-cholesterol, TG, BS, Hb1Ac, and Plt in patients with earIy NASH were different from those in patients with advanced NASH with statistical significance (Table 1). All patients with early and advanced NASH are shown in Supplementary Table 1 with individual clinical and histological data. The pharmacological effects of pioglitazone, bezafibrate, ezetimibe, and other medications were investigated in NASH patients. 


\section{Assay methods for serum levels of MMPs/TIMPs and cytokines}

The serum levels of MMP-1, MMP-2, MMP-9, TIMP-1, TIMP-2, SDF-1 $\alpha$, stem cell factor-1 (SCF-1), stem cell growth factor- $\beta$ (SCGF- $\beta$ ), monocyte chemotactic protein-1 (MCP-1), granulocytecolony stimulating factor (G-CSF), leptin, and ghrelin were measured by fluorescent beads-based immunoassay (Bio-Plex ${ }^{\circledR} 200$, Bio-Rad Laboratories Inc., Hercules, CA., USA) and kits including antibodies, detection antibodies, and standard controls were used. The mean of duplicate values was entered as the measurement data. Detection and analysis were performed according to the manufacturer's assay protocol. The serum cytokine concentrations from optical density were analyzed.

\section{Evaluation of disease activity relative to serum levels of MMPs/TIMPs and cytokines}

The ALT levels of NASH patients in clinical course were used to monitor disease activity. ${ }^{17}$ Serum levels of MMPs/TIMPs and cytokines were measured several times during the clinical course in 15 of 33 NASH patients. The 15 patients were divided into two groups, ALT improved and uncontrolled, and analysis conducted at $0,21,35,70$ weeks. Eight patients of the ALT improved group showed ALT levels $<30 \mathrm{IU} / \mathrm{L}$ on final observation at 70 weeks, and seven patients of the ALT uncontrolled group showed ALT levels $\geq 30 \mathrm{IU} / \mathrm{L}$ at 70 weeks. ALT values of the two groups were compared with serum levels of MMPs, TIMPs and cytokines at the same points in time.

\section{Pharmacological effect of pioglitazone on disease activity in NASH patients}

After serum HDL, TG, LDL and HbA1c stabilized by administration of lipid-lowering agents or anti-diabetic agents, we evaluated the effect of pioglitazone on disease activity. Seventeen NASH patients were treated with pioglitazone for over two months and serum levels of MMPs and TIMPs before and after treatment were measured. Clinical manifestation, physical findings and clinical hematological and biochemical data were compared with the serum levels of MMPs, TIMPs and cytokines before and after two months of $15 \mathrm{mg}$ pioglitazone administered once daily.

\section{Effects of extrahepatic inflammatory conditions on serum MMP-1 levels}

Patients with diabetes and/or metabolic syndrome, examined with repeated serum levels of MMP-1, were analyzed for the relationship between serum levels of MMP-1 and HbA1c value as well as some clinical findings of metabolic syndrome as the markers of extrahepatic inflammatory conditions seen in NASH patients.

Table 2. Serum levels of MMPS, TIMPs and cytokines in healthy controls and patients with early NASH and advanced NASH

\begin{tabular}{lccc} 
& $\begin{array}{c}\text { Healthy controls } \\
(\mathbf{n = 1 4 )}\end{array}$ & $\begin{array}{c}\text { Early NASH } \\
(\mathbf{n = 2 4 )}\end{array}$ & $\begin{array}{c}\text { Advanced NASH } \\
(\mathbf{n = 9})\end{array}$ \\
\hline MMP-1 $(\mathrm{ng} / \mathrm{mL})$ & $0.96 \pm 0.55$ & $1.71 \pm 1.63$ & $1.38 \pm 0.35$ \\
\hline MMP-2 $(\mathrm{ng} / \mathrm{mL})$ & $30.7 \pm 10.8$ & $33.5 \pm 12.4$ & $52.0 \pm 19.2^{*}$ \\
\hline MMP-9 $(\mathrm{ng} / \mathrm{mL})$ & $24.0 \pm 14.8$ & $33.7 \pm 25.7$ & $16.9 \pm 6.7$ \\
\hline TIMP-1 $(\mathrm{ng} / \mathrm{mL})$ & $119.5 \pm 24.1$ & $125.6 \pm 23.7$ & $150.7 \pm 38.8^{*}$ \\
\hline TIMP-2 $(\mathrm{ng} / \mathrm{mL})$ & $57.1 \pm 27.0$ & $54.2 \pm 10.0$ & $66.3 \pm 20.4$ \\
\hline SDF-1a $(\mathrm{pg} / \mathrm{mL})$ & $133.4 \pm 45.6$ & $230.2 \pm 182.4^{\dagger}$ & $371.3 \pm 227.5^{\dagger}$ \\
\hline SCF-1 $(\mathrm{pg} / \mathrm{mL})$ & $89.3 \pm 24.7$ & $100.2 \pm 46.1$ & $105.7 \pm 20.8$ \\
\hline SCGF- $3(\mathrm{ng} / \mathrm{mL})$ & $12.0 \pm 7.0$ & $18.0 \pm 13.6$ & $19.6 \pm 11.9^{\dagger}$ \\
\hline MCP-1 $(\mathrm{pg} / \mathrm{mL})$ & $35.2 \pm 10.4$ & $55.1 \pm 22.2^{*}$ & $54.2 \pm 23.6^{\dagger}$ \\
\hline G-CSF $(\mathrm{pg} / \mathrm{mL})$ & $0.25 \pm 0.81$ & $2.24 \pm 2.19^{*}$ & $1.24 \pm 2.07$ \\
\hline Leptin $(\mathrm{pg} / \mathrm{mL})$ & $2,348.5 \pm 2,831.2$ & $6,134.6 \pm 4,347.0^{\dagger}$ & $4,020.0 \pm 2.124 .6^{*}$ \\
\hline Ghrelin $(\mathrm{pg} / \mathrm{mL})$ & $325.4 \pm 161.2$ & $405.0 \pm 453.2$ & $219.1 \pm 227.2$ \\
\hline
\end{tabular}

Values indicate mean \pm standard deviation (SD).

MMP, matrix metalloproteinase; TIMP, tissue inhibitor of metalloproteinase; NASH, nonalcoholic steatohepatitis; SDF, stromal cell-derived factor; SCF, stem cell factor; SCGF- $\beta$, stem cell growth factor- $\beta$; MCP, monocyte chemotactic protein; G-CSF, granulocyte-colony stimulating factor.

Serum levels of MMPs/TIMPs and cytokines in NASH patients vs. those in healthy controls, ${ }^{*} P<0.05,{ }^{\dagger} P<0.01$. 


\section{Statistical analysis}

All statistical analyses were performed with EZR version 1.32 (Saitama Medical Center, Jichi Medical University), which is a graphic user interface for $\mathrm{R}$ (The R Foundation for Statistical Computing, version 2.2.0). ${ }^{18}$

Biomarkers were expressed as mean \pm standard deviation. Clinical data were post hoc Mann-Whitney $U$ test adjusted for multiple comparison with Bonferroni correction after Kruskal-Wallis analysis of variance. Comparison between controls and grades of cytokines was conducted by Steel's test. Spearman's rank correlation was used for correlation analysis of data. A $P$-value of less than 0.05 was regarded as statistically significant for all analyses.

\section{RESULTS}

\section{Serum levels of MMPs/TIMPs in patients with early and advanced NASH}

Serum levels of MMPs and TIMPs in patients with early NASH $(n=24)$ and advanced NASH $(n=9)$ were compared with those in
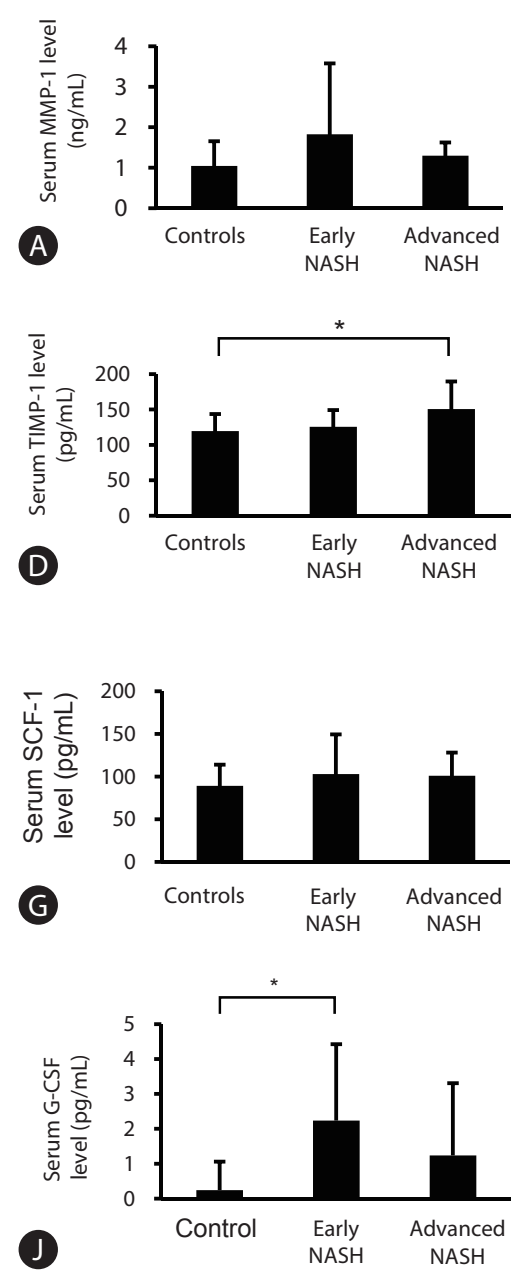


Figure 1. Comparison of serum MMPs, TIMPs, and cytokine levels in patients with early NASH/advanced NASH, and healthy controls. Serum levels of MMP-1 (A), MMP-2 (B), MMP-9 (C), TIMP-1 (D), TIMP-2 (E), SDF-1a (F), SCF-1 (G), SCGF- 3 (H), MCP-1 (I), G-CSF (J), Leptin (K), Ghrelin (L); Serum levels of MMP-1 and MMP-9 in early NASH patients tended to be higher than in patients with advanced NASH and in healthy controls but this was not statistically significant. The serum levels of MMP-2 and TIMP-1 in advanced NASH patients were statistically higher than in healthy controls. The serum levels of cytokines showed significantly higher values in NASH patients. MMP, matrix metalloproteinase; TIMP, tissue inhibitors of metalloproteinase; NASH, nonalcoholic steatohepatitis; SDF, stromal cell-derived factor; SCF, stem cell factor; SCGF- $\beta$, stem cell growth factor- $\beta$; MCP, monocyte chemotactic protein; G-CSF, granulocyte-colony stimulating factor. Statistical significance: " $P<0.05,{ }^{* *} P<0.01$. 
healthy controls $(n=14)$. Serum levels of MMP-1 and MMP-9 in early NASH patients showed a tendency to be higher than those in patients with advanced NASH and in healthy controls without statistical significance (Table 2, Fig. 1). The serum levels of MMP-2 in advanced NASH patients were statistically higher than those in early NASH patients and controls (Table 2, Fig. 1). The serum levels of TIMP-1 and TIMP-2 in advanced NASH patients were higher than in healthy controls and in early NASH patients (Table 2, Fig. 1).

\section{Relationship between Serum Levels of MMPs/TIMPs and Histological Findings in NASH Patients}

The serum levels of MMPs and TIMPs in patients with NASH by grade of histological characteristics of NASH, i.e., steatosis, inflammation, ballooning and fibrosis, were compared with those in healthy controls.

Serum levels of MMP-1: As shown in Table 3 and Fig. 2, the serum MMP-1 levels in stage 1 of fibrosis (F1 group) were higher than those in healthy controls with statistical significance $(P=0.019)$. However, there was no correlation between MMP-1 and stage of fibrosis (Supplementary Table 2). The serum MMP-1 levels in grade 2 of steatosis, and grades 1 and 2 of inflammation were higher than in healthy controls, but no correlation between serum level and grade of histological findings was observed.

Serum levels of MMP-2: Serum MMP-2 levels in the F4 group were higher than those in healthy controls with statistical difference $(P<0.01)$, as shown in Table 3 and Fig. 2. Grade 1 of steatosis, grade 3 of inflammation, grade 2 of ballooning and the F3 group showed that serum MMP-2 levels tended to be higher than in healthy controls. Some correlation between serum MMP-2 levels and stages of fibrosis was observed with statistical significance ( $P=0.051$ ) (Supplementary Table 2).

Serum levels of MMP-9: Similar to the serum levels of MMP1, serum levels of MMP-9 in grade 2 of steatosis, grade 2 of inflammation and $\mathrm{F} 1$ group tended to be higher than in healthy controls, as shown in Table 3 and Fig. 2. There was no correlation between serum MMP-9 level and grade of histological findings (Supplementary Table 2).

Serum levels of TIMPs: Similar to serum levels of MMP-2, serum levels of TIMP-1 in the F4 group were significantly higher than those in healthy controls, as shown in Table 3 and Fig. 2 $(P<0.01)$. Grade 2 of steatosis, grade 3 of inflammation and grade 2 of ballooning showed a higher tendency of serum TIMP-1 levels. Serum levels of TIMP-2 in grade 3 of inflammation and the F4 group showed a slightly higher tendency than in healthy controls. A statistically significant correlation between serum TIMP-1 levels and the stages of fibrosis was observed $(P=0.038)$.

\section{Serum levels of cytokines in patients with NASH}

As it has been reported that, in the progression of NASH, HSCS, $\mathrm{KCS}$ and endothelial cells (ECs) are activated by cytokines via

Table 3. Serum levels of MMPs and TIMPs in NASH patients by grade of histological characteristics compared with those in healthy controls

\begin{tabular}{|c|c|c|c|c|c|c|}
\hline & & MMP-1 (ng/mL) & MMP-2 (ng/mL) & MMP-9 (ng/mL) & TIMP-1 (ng/mL) & TIMP-2 (ng/mL) \\
\hline Healthy controls & & $1.28 \pm 1.08$ & $33.2 \pm 13.6$ & $28.0 \pm 24.6$ & $119.5 \pm 24.7$ & $57.1 \pm 40.5$ \\
\hline \multirow[t]{3}{*}{ Steatosis } & 1 & $1.27 \pm 0.83$ & $42.2 \pm 15.8$ & $22.8 \pm 20.2$ & $123.4 \pm 22.7$ & $58.6 \pm 15.0$ \\
\hline & 2 & $1.71 \pm 1.93$ & $37.5 \pm 18.3$ & $32.0 \pm 27.6$ & $135.9 \pm 34.3$ & $57.0 \pm 15.9$ \\
\hline & 3 & $1.24 \pm 1.14$ & $37.2 \pm 15.9$ & $27.7 \pm 9.0$ & $133.1 \pm 32.5$ & $57.7 \pm 13.7$ \\
\hline \multirow[t]{3}{*}{ Inflammation } & 1 & $1.52 \pm 1.77$ & $39.5 \pm 18.3$ & $35.1 \pm 33.9$ & $122.0 \pm 21.0$ & $56.3 \pm 13.8$ \\
\hline & 2 & $1.67 \pm 1.68$ & $35.8 \pm 13.6$ & $23.1 \pm 13.6$ & $131.7 \pm 22.8$ & $54.4 \pm 9.7$ \\
\hline & 3 & $0.96 \pm 0.44$ & $46.5 \pm 26.1$ & $33.7 \pm 11.8$ & $169.6 \pm 60.8$ & $73.5 \pm 27.2$ \\
\hline \multirow[t]{2}{*}{ Ballooning } & 1 & $1.18 \pm 1.53$ & $40.2 \pm 16.5$ & $16.5 \pm 18.5$ & $116.5 \pm 16.3$ & $51.0 \pm 11.2$ \\
\hline & 2 & $1.39 \pm 0.92$ & $43.0 \pm 21.7$ & $21.7 \pm 15.0$ & $141.2 \pm 42.5$ & $63.2 \pm 19.5$ \\
\hline \multirow[t]{4}{*}{ Fibrosis } & 1 & $2.09 \pm 0.66^{*}$ & $36.7 \pm 15.5$ & $38.6 \pm 29.1$ & $124.7 \pm 16.8$ & $53.4 \pm 9.8$ \\
\hline & 2 & $0.85 \pm 0.48$ & $29.1 \pm 4.8$ & $26.8 \pm 21.1$ & $126.9 \pm 32.8$ & $55.3 \pm 11.3$ \\
\hline & 3 & $0.64 \pm 0.20$ & $43.2 \pm 6.8$ & $14.6 \pm 3.7$ & $120.8 \pm 14.2$ & $50.5 \pm 13.3$ \\
\hline & 4 & $0.80 \pm 0.40$ & $56.5 \pm 23.9^{\dagger}$ & $18.0 \pm 8.4$ & $165.6 \pm 42.8^{\dagger}$ & $74.1 \pm 21.3$ \\
\hline
\end{tabular}

Values indicate mean \pm standard deviation (SD).

MMP, matrix metalloproteinase; TIMP, tissue inhibitors of metalloproteinase; NASH, nonalcoholic steatohepatitis.

Significant difference between serum levels of MMPs/TIMPs in NASH patients vs. those in healthy controls: ${ }^{*} P<0.05,{ }^{\dagger} P<0.01$. 
paracrine and autocrine manner. The serum levels of SDF-1 $\alpha$, SCGF- $\beta$, SCF-1, G-CSF, MCP-1, leptin, and ghrelin were measured in both of early and advanced NASH patients.

Serum levels of SDF-1 $\alpha$ : The serum levels of SDF-1 $\alpha$ in both early and advanced NASH patients were significantly higher than in controls $(P<0.001)$ (Table 2 and Fig. 1).

Grades 1 and 2 of steatosis, grades 2 and 3 of inflammation, grades 1 and 2 of ballooning, F2, F3 and F4 groups showed significantly higher levels compared with those in healthy controls; notably the F4 group with clinical liver cirrhosis had the highest levels, as shown in Table 4. The correlations between serum level of SDF- $1 \alpha$ and grade of every histological finding (steatosis, inflammation, ballooning and fibrosis) were all statistically significant $(P=0.005, P<0.001, P=0.002$ and $P<0.001$, respectively) (Supplementary Table 2).

Serum levels of SCGF- $\beta$ : Serum SCGF- $\beta$ levels in advanced NASH patients were significantly higher than in controls $(P=0.001)$ (Table 2 and Fig. 1). Grade 2 of steatosis, grades 2 and 3 of in-
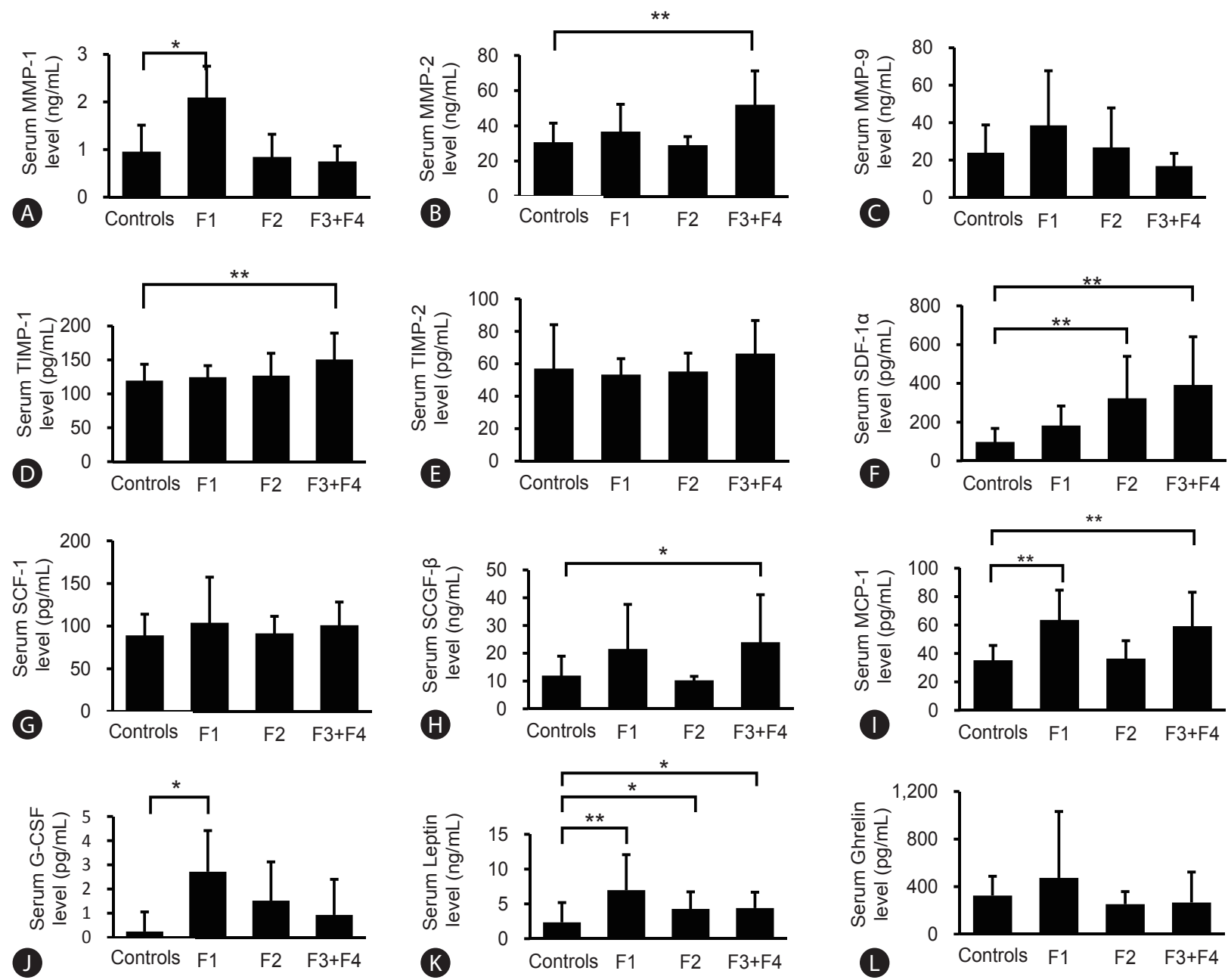

Figure 2. Serum levels of MMPs, TIMPS, and cytokines in NASH patients by fibrosis stage compared with those in healthy controls. Serum levels of MMP-1 (A), MMP-2 (B), MMP-9 (C), TIMP-1 (D), TIMP-2 (E), SDF-1a (F), SCF-1 (G), SCGF- $\beta$ (H), MCP-1 (I), G-CSF (J), Leptin (K), Ghrelin (L). The numbers of patients were as follows: F1 NASH group ( $n=14)$, F2 NASH group ( $n=10)$, F3+F4 NASH groups $(n=9)$, and healthy controls ( $n=14)$. The serum MMP-1 levels in fibrosis stage 1 (F1 group) were higher $(P<0.01)$, the serum MMP-2 levels in the F4 group were higher $(P<0.01)$, the serum levels of TIMP-1 in the F4 group were also significantly higher than those in healthy controls $(P<0.01)$. Serum levels of SDF-1a were significantly higher in the F2, F3 and F4 groups. Serum levels of G-CSF in the F3 group were statistically higher than in healthy controls. Serum levels of MCP-1 and serum levels of leptin in the F1 group were statistically higher compared with healthy controls. F, fibrosis; MMP, matrix metalloproteinase; TIMP, tissue inhibitors of metalloproteinase; SDF, stromal cell-derived factor; SCF, stem cell factor; SCGF- $\beta$, stem cell growth factor- $\beta$; MCP, monocyte chemotactic protein; G-CSF, granulocyte-colony stimulating factor; $\mathrm{NASH}$, nonalcoholic steatohepatitis. Statistical significance: ${ }^{*} P<0.05,{ }^{* \prime \prime} P<0.01$. 
Table 4. Serum levels of cytokines in NASH patients by grade of histological characteristics compared with those in healthy controls

\begin{tabular}{|c|c|c|c|c|c|c|c|c|}
\hline & & $\begin{array}{l}\text { SDF-1a } \\
(\mathrm{pg} / \mathrm{mL})\end{array}$ & $\begin{array}{c}\text { SCF-1 } \\
(\mathrm{pg} / \mathrm{mL})\end{array}$ & $\begin{array}{l}\text { SCGF- } \beta \\
(\mathrm{ng} / \mathrm{mL})\end{array}$ & $\begin{array}{c}\text { MCP-1 } \\
\text { (pg/mL) }\end{array}$ & $\begin{array}{c}\text { G-CSF } \\
(\mathrm{pg} / \mathrm{mL})\end{array}$ & $\begin{array}{l}\text { Leptin } \\
\text { (ng/mL) }\end{array}$ & $\begin{array}{l}\text { Ghrelin } \\
\text { (pg/mL) }\end{array}$ \\
\hline Healthy controls & & $97.8 \pm 77.9$ & $89.3 \pm 26.8$ & $12 \pm 10$ & $35.2 \pm 11.6$ & $0.24 \pm 0.81$ & $2.35 \pm 1.91$ & $325.4 \pm 157.2$ \\
\hline \multirow[t]{3}{*}{ Steatosis } & 1 & $302.0 \pm 215.0^{\dagger}$ & $117.9 \pm 63$ & $16.2 \pm 8.2$ & $52.2 \pm 25.3$ & $2.94 \pm 6.21$ & $5.42 \pm 5.84$ & $478.5 \pm 698.7$ \\
\hline & 2 & $322.5 \pm 206.8^{\dagger}$ & $98.3 \pm 26$ & $20.9 \pm 15.9$ & $53.2 \pm 20.7^{*}$ & $2.00 \pm 2.37$ & $4.97 \pm 2.53$ & $310.5 \pm 191.6$ \\
\hline & 3 & $115.2 \pm 77.5$ & $88.2 \pm 7.3$ & $14.8 \pm 3.6$ & $64.9 \pm 25.7^{*}$ & $3.25 \pm 1.29$ & $6.70 \pm 4.01$ & $188.8 \pm 126.5$ \\
\hline \multirow[t]{3}{*}{ Inflammation } & 1 & $233.8 \pm 109.5^{*}$ & $113.2 \pm 55.2$ & $14.6 \pm 7.0$ & $51.5 \pm 24.0$ & $1.66 \pm 2.29$ & $4.83 \pm 3.34$ & $274.4 \pm 142.3$ \\
\hline & 2 & $319.3 \pm 263.7^{\dagger}$ & $89.8 \pm 18.7$ & $21.6 \pm 16.0$ & $59.5 \pm 22.2^{\dagger}$ & $3.44 \pm 4.71^{*}$ & $5.82 \pm 4.46$ & $430.9 \pm 544.5$ \\
\hline & 3 & $327.5 \pm 192.9$ & $115.3 \pm 18.1$ & $20.1 \pm 13.4$ & $46.9 \pm 18.6$ & $1.24 \pm 1.17$ & $5.42 \pm 3.24$ & $179.2 \pm 120.9$ \\
\hline \multirow[t]{2}{*}{ Ballooning } & 1 & $254.5 \pm 151.8^{*}$ & $108.8 \pm 48.7$ & $15.6 \pm 7.6$ & $51.2 \pm 26.9$ & $2.21 \pm 4.57$ & $5.07 \pm 3.04$ & $304.2 \pm 211.2$ \\
\hline & 2 & $237.4 \pm 242.6^{\dagger}$ & $93.7 \pm 17.8$ & $22.4 \pm 16.9^{*}$ & $59.4 \pm 14.2^{\dagger}$ & $2.78 \pm 2.08$ & $5.76 \pm 4.71^{*}$ & $381.2 \pm 554.6$ \\
\hline \multirow[t]{4}{*}{ Fibrosis } & 1 & $182.7 \pm 100.7$ & $104.1 \pm 54.5$ & $21.6 \pm 15.2$ & $63.6 \pm 20.6^{\dagger}$ & $2.72 \pm 2.53^{*}$ & $6.98 \pm 4.84^{\dagger}$ & $474.4 \pm 535.4$ \\
\hline & 2 & $323.4 \pm 216.0^{\dagger}$ & $91.6 \pm 19.9$ & $10.3 \pm 1.4$ & $36.4 \pm 12.5$ & $1.53 \pm 1.81$ & $4.28 \pm 2.44^{*}$ & $252.5 \pm 105.6$ \\
\hline & 3 & $344.1 \pm 241.9^{*}$ & $103.8 \pm 20.7$ & $21.6 \pm 12.9$ & $56.6 \pm 31.5$ & $1.18 \pm 1.09$ & $5.29 \pm 2.33^{*}$ & $160.4 \pm 278.4$ \\
\hline & 4 & $430.7 \pm 274.0^{\dagger}$ & $107.2 \pm 23.2$ & $18.0 \pm 12.3$ & $52.3 \pm 18.8$ & $0.79 \pm 1.76$ & $3.01 \pm 1.43$ & $266.1 \pm 197.1$ \\
\hline
\end{tabular}

Values indicate mean \pm standard deviation (SD).

NASH, nonalcoholic steatohepatitis; SDF, stromal cell-derived factor; SCF, stem cell factor; SCGF- $\beta$, stem cell growth factor- $\beta$; MCP, monocyte chemotactic protein; G-CSF, granulocyte-colony stimulating factor.

Serum levels of cytokines in NASH patients vs. those in healthy controls, ${ }^{*} P<0.05,{ }^{\dagger} P<0.01$.

flammation, grade 2 of ballooning, F1 and F3 groups tended to show higher levels (Table 4, Fig. 2). Serum SCGF- $\beta$ levels did not parallel levels of serum SDF-1 $\alpha$. Notably, serum SCGF- $\beta$ levels of the F4 group were not high. The correlation between serum SCGF- $\beta$ levels and the grades of steatosis, inflammation and ballooning was significant $(P=0.025, P=0.012$ and $P=0.008$, respectively) (Supplementary Table 2). With the exception of the F4 group, serum SCGF- $\beta$ levels were very similar to those for SDF- $1 \alpha$.

Serum levels of SCF-1: Serum levels of SCF-1 tended to be higher in grade 1 of steatosis, grades 1 and 3 of inflammation, grade 1 of ballooning and the F1, F3 and F4 groups (Table 4 and Fig. 2). Grade 2 of steatosis, grades 1 and 3 of inflammation, and F1, F3 and F4 groups showed a slightly higher tendency (Table 4, Fig. 2). No correlation between serum SCF-1 level and grade of histological finding was observed (Supplementary Table 2). Serum SCF-1 levels did not parallel serum SDF-1 $\alpha$ and SCGF- $\beta$ levels.

Serum levels of G-CSF: Serum levels of G-CSF were statistically higher in early NASH (Table 2, Fig. 1). Serum levels of G-CSF in grade 2 of inflammation and $\mathrm{F} 3$ group were statistically higher than in healthy controls (Table 4, Fig. 2). All grades of steatosis, grades 1 and 3 of inflammation, grades 1 and 2 of ballooning, and the F1 and F2 groups showed higher serum levels of G-CSF with no statistical difference (Table 4, Fig. 2). Among these data, it is of special interest that the $\mathrm{F} 3$ group showed the highest levels of G-CSF, but the F4 group showed the same levels as those of healthy controls. No correlation between serum G-CSF level and grade of any histological finding was observed (Supplementary Table 2). Serum levels of G-CSF were very similar to those of SCF1 and MCP-1, except in the F4 group.

Serum levels of MCP-1: Serum levels of MCP-1 in early and advanced NASH were higher than in healthy controls with statistical difference $(P<0.05$ and $P<0.01$, respectively) (Table 2, Fig. 1). Serum levels of MCP-1 were significantly higher for grades 2 and 3 of steatosis, grade 2 of inflammation, grade 2 of ballooning and the F1 group than in healthy controls (Table 4, Fig. 2). Statistically significant correlation between serum levels of MCP-1 and all grades of histological findings, steatosis, inflammation, ballooning and fibrosis, was observed $(P=0.002, P=0.005, P=0.001$ and $P=0.046$, respectively) (Supplementary Table 2). Serum levels of MCP-1 were very similar to those of SDF-1 $\alpha$ and SCGF- $\beta$.

Serum levels of leptin: Serum levels of leptin were significantly higher in both early and advanced NASH than in healthy controls $(P<0.01$ and $P<0.05$, respectively), as shown in Table 2 and Fig. 1. Serum levels of leptin by grade of steatosis and inflammation were elevated with no statistical difference (Table 4). Grade 2 of ballooning and the F1 group showed statistically higher levels of leptin compared with healthy controls, as shown in Table 4 and Fig. 2. Statistically significant correlation between se- 

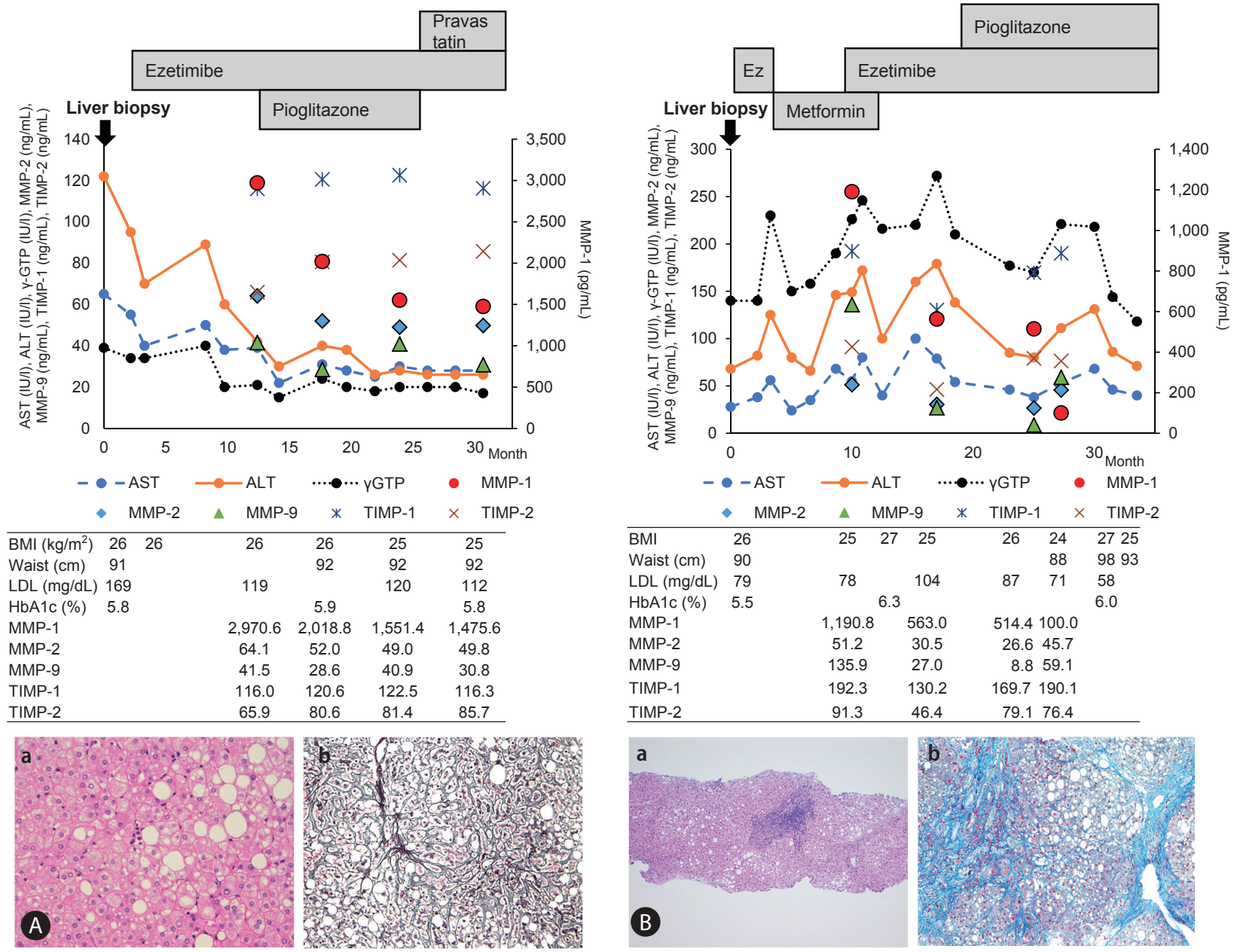

Figure 3. Clinical course of one early and one advanced NASH patient. (A) Early NASH patient. (A-a) HE staining (X100). (A-b) Silver impregnation ( $\times 100)$. (B) Advanced NASH patient. (B-a) HE staining ( $\times 100)$. (B-b) Mallory's Azan staining ( $\times 100)$. NASH, nonalcoholic steatohepatitis; AST, aspartate aminotransferase; ALT, alanine aminotransferase; $\gamma$-GTP, gamma-glutamyl transpeptidase; MMP, matrix metalloproteinase; TIMP, tissue inhibitors of metalloproteinase; BMl, body mass index; LDL, low-density lipoprotein cholesterol; HbAlc, hemoglobin Alc; HE, hematoxylin and eosin stain.

rum levels of leptin and all grades of histological findings, steatosis, inflammation, ballooning and fibrosis, was observed ( $P=0.001, P=0.002, P=0.004$ and $P=0.038$, respectively) (Supplementary Table 2). Serum levels of leptin were similar to those of SDF- $1 \alpha$, SCGF- $\beta$ and MCP- 1 except in the various stages of fibrosis. Serum levels of leptin appear to be related to steatosis and inflammation.

Serum levels of ghrelin: Serum levels of ghrelin were the same as those in healthy controls (Table 2 and Fig. 1). Serum levels of ghrelin were unique for all grades of histological findings because they were the reverse of those in healthy controls but without statistical difference (Table 4). The correlation of serum levels and all grades of histological findings also showed an inverse relationship with no statistical difference (Supplementary Table 2).

\section{Serum levels of MMPs/TIMPs and cytokines in relation to the clinical course of NASH patients}

Although we could not perform repeated liver biopsies on the same patient, disease activity in NASH was determined to some extent using serum ALT. Overeating, increase in body weight and low physical activity cause increase of serum ALT so we investigated whether changes in serum MMPs, TIMPs and cytokine levels occurred relative to changes in serum ALT in individual cases. It is necessary to further clarify whether increase in ALT accompanies changes in serum cytokines resulting in changing levels of MMPs and/or TIMPs.

Clinical course of two patients: We present here the clinical course of two patients, one in early stage NASH and the other 
Table 5. Serum MMPS/TIMPs and SDF-1a changes in the ALT improved group and ALT uncontrolled group

\begin{tabular}{|c|c|c|c|c|c|}
\hline & & \multicolumn{4}{|c|}{ Weeks } \\
\hline & & 0 & 21 & 35 & 70 \\
\hline \multirow[t]{7}{*}{ ALT improved group $(n=8)$} & $\mathrm{ALT}(\mathrm{IU} / \mathrm{L})$ & $54.9 \pm 35.4$ & $26.0 \pm 9.8$ & $34.3 \pm 13.2$ & $25.3 \pm 12.9$ \\
\hline & MMP-1 (ng/mL) & $2,404.2 \pm 2,230.8$ & $1,805.9 \pm 1366.4$ & $743.9 \pm 582.6$ & $828.1 \pm 594.5$ \\
\hline & MMP-2 (ng/mL) & $36.4 \pm 12.4$ & $26.0 \pm 14.5$ & $36.0 \pm 16.0$ & $36.0 \pm 3.9$ \\
\hline & MMP-9 (ng/mL) & $33.5 \pm 37.3$ & $12.2 \pm 9.2$ & $34.0 \pm 16.0$ & $34.0 \pm 5.2$ \\
\hline & TIMP-1 (ng/mL) & $131.9 \pm 25.3$ & $122.6 \pm 16.0$ & $132.0 \pm 7.2$ & $132.0 \pm 37.5$ \\
\hline & TIMP-2 (ng/mL) & $60.7 \pm 8.9$ & $73.5 \pm 5.0$ & $61.0 \pm 7.3$ & $61.0 \pm 2.1$ \\
\hline & SDF-1a (pg/mL) & $313.5 \pm 222.6$ & $325.9 \pm 113.8$ & $314.0 \pm 57.1$ & $314.0 \pm 145.4$ \\
\hline \multirow[t]{7}{*}{ ALT uncontrolled group $(n=7)$} & ALT (IU/L) & $80.4 \pm 29.4$ & $49.8 \pm 23.4$ & $48.3 \pm 20.0$ & $72.3 \pm 26.7$ \\
\hline & MMP-1 (ng/mL) & $1,387.1 \pm 877.0$ & 1,453.0土1,198.6 & $1,059.0 \pm 761.9$ & $962.3 \pm 794.8$ \\
\hline & MMP-2 (ng/mL) & $28.0 \pm 6.9$ & $32.3 \pm 25.9$ & $22.5 \pm 8.0$ & $36.8 \pm 16.0$ \\
\hline & MMP-9 (ng/mL) & $32.4 \pm 19.3$ & $21.9 \pm 15.5$ & $11.6 \pm 2.8$ & $41.1 \pm 29.7$ \\
\hline & TIMP-1 (ng/mL) & $126.9 \pm 16.1$ & $147.3 \pm 20.5$ & $118.9 \pm 10.0$ & $158.4 \pm 16.0$ \\
\hline & TIMP-2 (ng/mL) & $54.9 \pm 16.3$ & $81.0 \pm 9.3$ & $60.7 \pm 17.6$ & $78.7 \pm 11.5$ \\
\hline & SDF-1a (pg/mL) & $135.2 \pm 71.6$ & $365.5 \pm 211.3$ & $135.0 \pm 34.5$ & $464.2 \pm 338.2$ \\
\hline
\end{tabular}

Values indicate mean \pm standard deviation (SD). No statistical significance between the two groups in serum levels of ALT, MMPs/TIMPs at 0, 21, 35 and 70 weeks.

MMP, matrix metalloproteinase; TIMP, tissue inhibitors of metalloproteinase; SDF, stromal cell-derived factor; ALT, alanine aminotransferase.

in advanced stage, in order to obtain a better understanding of the disease activity of NASH. The first case was a 38-year-old man suffering from NAFLD due to metabolic syndrome (BMI 25.9, waist $91 \mathrm{~cm}$ ) since 2009. Liver biopsy performed in March 2014 revealed diffuse steatosis with large droplets in hepatocytes in the pericentral region and intermediate zone with small lymphocyte infiltration, suggesting steatosis grade 3 , inflammation grade 1 , ballooning grade 2 and fibrosis stage 1 . We categorized this patient as being in an early stage of NASH (Fig. 3A, No.13 in Supplementary Table 1). He had hyperlipidemia and received ezetimibe, which decreased LDL (Fig. 3A) and triglyceride (not shown). As ALT was still high after 10 months of ezetimibe treatment, the anti-insulin-resistant agent pioglitazone (15 mg/day) was prescribed. Fourteen months of treatment with pioglitazone and ezetimibe gradually lowered ALT level to a normal value of $20 \mathrm{IU} / \mathrm{L}$. AST and $\gamma$-GTP in serum also improved. Serum levels of MMP-1 and MMP9 decreased gradually, as shown in Fig. 3A.

Figure 3B shows the clinical course of a 46-year-old man with metabolic syndrome (BMI 26, waist $90 \mathrm{~cm}$ ) who was diagnosed as advanced NASH by liver biopsy in July 2013 (Supplementary Table 1, No. 6). Histological findings revealed remarkable lymphocyte infiltration in the portal region, mild proliferation of bile ductules and bridging fibrosis. The patient had hyperlipidemia and elevated fast blood sugar and HbA1c levels. He also suffered from depression resulting in excess eating and lowered physical activity that altered ALT, AST and $\gamma$-GTP levels. The changes in ALT values did not correlate with serum levels of MMP-1, but lowered MMP-1 levels preceded decrease in ALT in this patient.

ALT improved group vs. ALT uncontrolled group: The principles of NASH treatment are proper diet and physical activity. If abnormal values of serum TG, and/or LDL were seen in individual laboratory data, lipid- lowering agents such as hydroxymethylglutaryl-CoA reductase inhibitor, bezafibrate and ezetimibe were prescribed. If the patients had diabetes mellitus, the appropriate anti-diabetes reagents were prescribed according to the guidelines of the Japan Diabetes Association (2016). Most NAFL patients showed a good clinical course following these treatments. If the NASH patients in this study did not improve, the anti-insulin-resistant agent pioglitazone was administered.

In 15 of 33 NASH patients serum levels of MMPs/TIMPs and cytokines were measured at $0,21,35,70$ weeks after liver biopsy during the clinical course. ALT values were compared with serum levels of MMPS, TIMPs and SDF-1 $\alpha$ at the same time.

The ALT improved group $(n=8)$ showed ALT values of less than $30 \mathrm{IU} / \mathrm{L}$ at 70 weeks, and decreased serum levels of MMP-1 level although statistical significance was not observed (Table 5, Fig. 4). On the other hand, serum levels of MMP-1 in seven patients of the ALT uncontrolled group either showed no change or were ele- 
ALT improved group

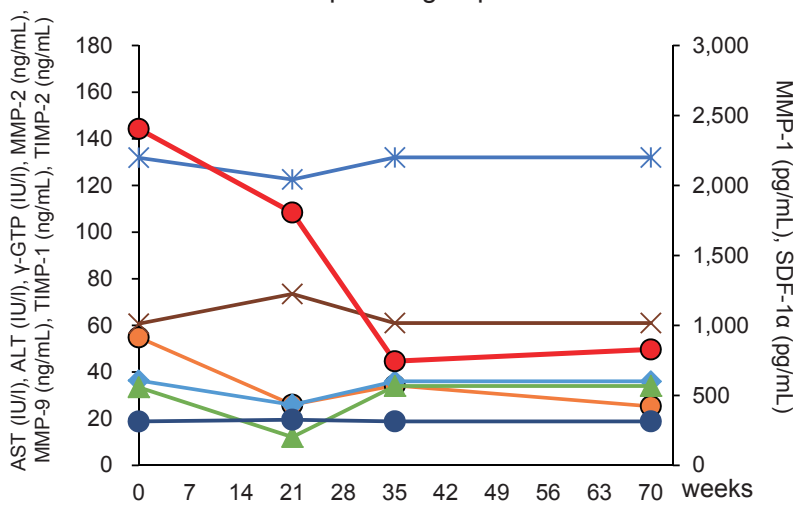

A $\quad \rightarrow$ ALT $\rightarrow$ MMP-1 $\longrightarrow$ MMP-2 $\leftarrow$ MMP-9
ALT uncontrolled group

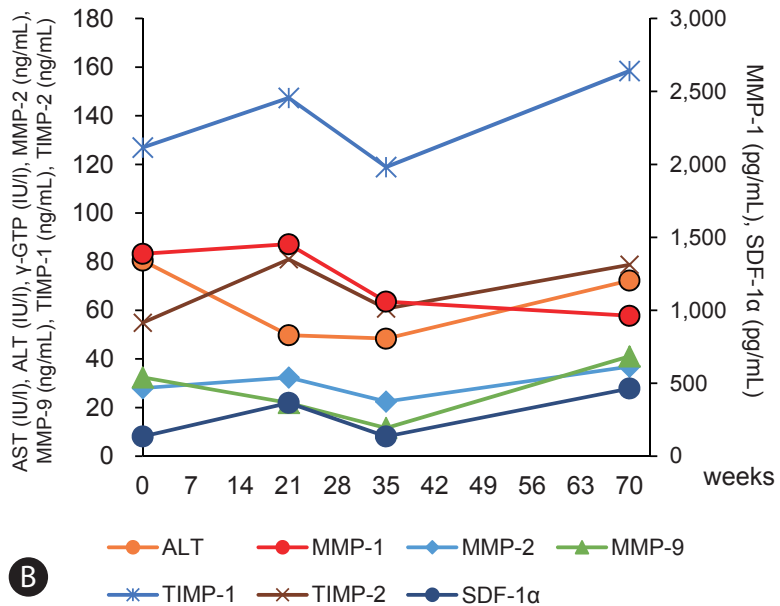

Figure 4. Clinical course of the ALT improved group (A) and ALT uncontrolled group (B): relation of ALT changes with serum levels of MMPs/TIMPS and SDF-1a. There were 8 patients in the ALT improved group and 7 patients in the ALT uncontrolled group. Each plot indicates mean value of each group. All data are given in Table 5. AST, aspartate aminotransferase; ALT, alanine aminotransferase; $Y$-GTP, gamma-glutamyl transpeptidase; MMP, matrix metalloproteinase; TIMP, tissue inhibitors of metalloproteinase; SDF, stromal cell-derived factor.

vated in the observed clinical course, as shown in Table 5 and Fig. 4. Moreover, the serum levels of MMP-1 at 70 weeks in the ALT improved group were lower than those in the ALT uncontrolled group without significance. This leads us to believe that serum level of MMP-1 in patients with NASH may be a useful indicator of the progression of the disease.

\section{Pharmacological effects on serum ALT, MMPs, TIMPs and SDF-1 $\alpha$ levels before and after administration of pioglitazone}

The numbers of NASH patients treated with pioglitazone for more than two months and determined for serum levels of MMPs, TIMPs and SDF1- $\alpha$ were as follows: 6 patients of the F1 group, 9 patients of the F2 group, one of the F3 group and one of the F4 group (Supplementary Tables 1 and 3). Clinical manifestations, physical findings and clinical hematological data showed no changes before and after pioglitazone treatment for two months.

ALT levels tended to decrease in the F1 and F2 NASH patients after pioglitazone administration $(P=0.225, P=0.074$, respectively) (Supplementary Table 3). Serum levels of MMP-1 in F1 NASH patients tended to decrease markedly after pioglitazone treatment for two months but those in F2 NASH patients showed either no change or slight decrease (Supplementary Table 3, Fig. 5). Serum levels of MMP-9 in the F2 group showed some decrease, but serum MMP-2, TIMP-1, and TIMP-2 levels exhibited no difference before and after pioglitazone administration (Supplementary Table
3, Fig. 5). Serum SDF-1 $\alpha$ levels in F1 NASH patients increased after pioglitazone administration (Supplementary Table 3, Fig. 5) with no significant difference $(P=0.110)$. There was no change in F2 NASH patients.

\section{Effects of extrahepatic inflammatory conditions on serum MMP-1 levels}

Patients with NASH are often accompanied by atherosclerosis, diabetes, and cardiovascular disease. The numbers of NASH patients examined with repeated serum levels of MMP-1 were 15. Seven cases had neither diabetes nor metabolic syndrome. Five cases had diabetes and metabolic syndrome. All of them belong to ALT uncontrolled group. The rest 3 cases had metabolic syndrome alone (Supplementary Table 1).

The relationship between serum MMP-1 levels and HbA1c: Five diabetes patients in ALT uncontrolled group showed a slightly higher $\mathrm{HbA1c}$ levels between 5.8 to 6.6\%. Serum MMP1 levels in ALT uncontrolled group was not correlated with changing $\mathrm{HbA1C}$ and ALT.

The relationship between serum MMP-1 levels and clinical findings of metabolic syndrome: Three NASH patients with metabolic syndrome belong to in ALT improved group. Two of them showed a decrease in serum MMP-1 levels according to decreasing ALT level and body weight. One patient showed no parallel serum levels of MMP-1 although body weight decreased. The rest 5 NASH patients with metabolic syndrome were compli- 

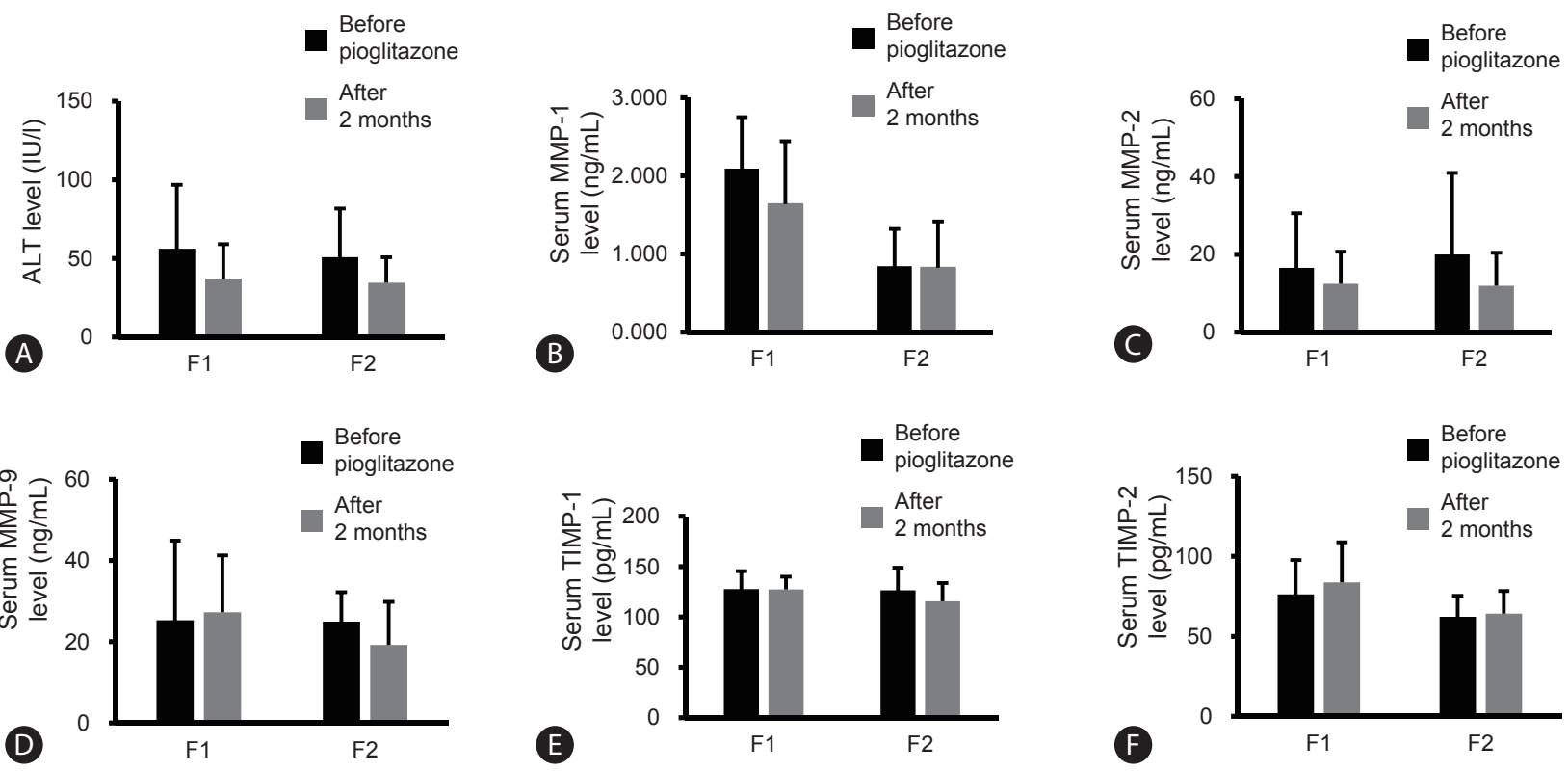

(D)
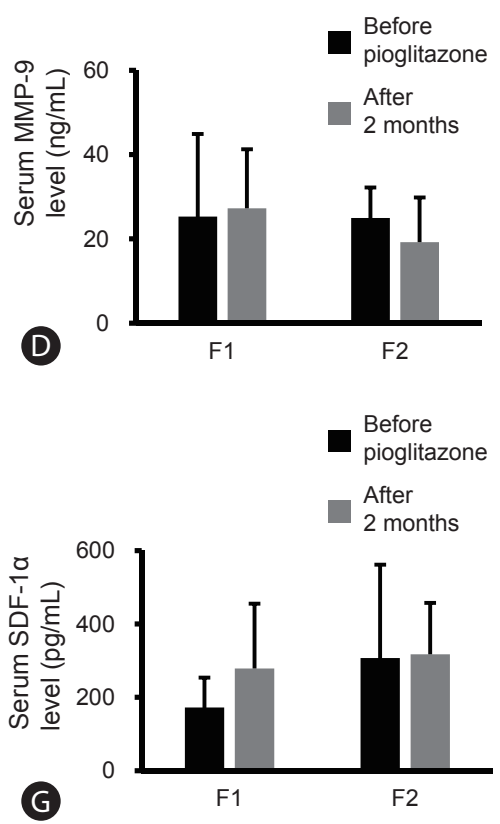

Figure 5. Effect of pioglitazone administration for two months on serum levels of MMPs/TIMPs and SDF-1a in the F1 and F2 groups. Number of F1 patients, 6; number of F2 patients, 9. Serum levels of ALT (A), MMP-1 (B), MMP-2 (C), MMP-9 (D), TIMP-1 (E), TIMP-2 (F), SDF-1a (G). ALT, alanine aminotransferase; MMP, matrix metalloproteinase; TIMP, tissue inhibitors of metalloproteinase; SDF, stromal cell-derived factor; F, fibrosis. cated with diabetes. All of them belong to ALT uncontrolled group. One of 5 patients showed decrease in body weight and serum levels of MMP-1, but ALT increased. Similarly, changing in waist circumference and blood pressure, serum levels of LDL-cholesterol and triglyceride was not consistent with serum MMP-1 levels.

\section{DISCUSSION}

We reported previously MMP-1 expression in MCs, KCs and HSCs in early NASH, and in HPCs and HSCs in advanced NASH by $\mathrm{IHC}$ and IEM observation. Our study suggests that MMP-1 expression can activate $\mathrm{KCS}, \mathrm{HSCs}, \mathrm{ECs}$ and HPCs, and transform these cells into ductular cells, myofibroblasts and elongated repaired endothelial cells, leading to fibrosis and angiogenesis. ${ }^{8}$ We then measured the serum levels of MMP-1 in patients with NASH. As shown in Fig. 3, changes in ALT values paralleled the serum levels of MMP-1. Our intention was to investigate the serum levels of MMP-1 in NASH patients relative to ALT values, which to some extent reflect the disease activity of NASH. ${ }^{6}$

The present study showed the following novel finding: serum MMP-1 levels were statistically higher in F1 NASH patients than in the F2 to F4 NASH patients and healthy controls. This increase in MMP-1 in the early stage of NASH appears to parallel the intensity of MMP-1 staining in MCS, KCs and HSCs by IHS and IEM. Deposits of triglyceride in hepatocytes cause steatosis and inflammation in early stage of NASH. Thus oxidative stress and apoptosis of hepatocytes may lead to infiltration of MCs and KCs. ${ }^{4,5,8}$ MMP-1 expression in MCs, KCs and HSCs may be caused by cytokines, as described below, and MMP-1 expression was seen in these cells.

Among MMPs/TIMPs and cytokines, the serum level of MMP-1 best reflected disease activity in the clinical course of NASH. Oxidative stress in mitochondria is an essential trigger in the pathogenesis of NASH in which serum levels of MMP-1 are reflected 
and serum levels of MMP-9 are related to the grades of steatosis and inflammation. The exact localization has not been observed in human study, but the cells responsible for producing MMP-9 may be hematopoietic stem cells and their derivative granulocytes. ${ }^{19}$ In the present study, however, serum levels of MMP-9 in NASH patients did not parallel the disease activity. Serum levels of MMP-2, TIMP-1 and TIMP-2 indicated progression of fibrosis but did not reflect steatosis and inflammation in the present study. Miele et al. ${ }^{20}$ and Toyoda et al. ${ }^{21}$ reported higher serum levels of MMP-2 and TIMPs, but they did not examine these values in relation to disease activity.

Next we compared serum levels of MMPs and TIMPs with serum levels of cytokines, i.e., SDF- $1 \alpha$, SCGF- $\beta$, SCF-1, MCP-1, GCSF, leptin, and ghrelin, in patients with NASH from the viewpoint of histological grading relative to the progression of NASH. Among these cytokines, serum levels of SDF-1 $\alpha$ and SCGF- $\beta$ were very similar to each other while serum levels of SCF-1, MCP-1, G-CSF and leptin were similar. The former group also showed levels similar to those of MMP-2 and TIMPs, and the latter reflected the beginning of steatosis with inflammation. Serum levels of ghrelin were very different from those of the other cytokines.

We measured the levels of the seven above cytokines. Each cytokine has a different physiological function. Marra and Tacke reported that KCs, injured hepatocytes, and activated HSCs secrete high levels of MCP-1, which promote the hepatic accumulation of bone marrow-derived CCR2-expressing MCs that massively expand the local macrophage pool. ${ }^{22}$ In the present study significantly higher serum levels of MCP-1 were observed at an early stage, probably the beginning stage of NASH subsequent to steatosis of hepatocytes. G-CSF has been reported to prevent the development of hepatic steatosis in rat NASH models. ${ }^{23}$ Moreover, acute liver failure in rats by D-galactosamine revealed that G-CSF enhanced SDF-1 gradient between bone marrow and liver inducing the chemo-attraction of CD34+ cells from bone marrow to an injured liver. ${ }^{24}$ Although this model was not a NASH model, G-CSF may cause increased levels of SDF-1.

SDF-1 is the main regulating factor for trafficking and homing of hematopoietic stem cells to the bone marrow. ${ }^{25}$ Sinusoidal endothelial cells are one of the main cellular sources of SDF-1 in the liver, and the SDF-1/CXCR4 axis is involved in the regulation of hematopoietic stem cell migration to the liver. ${ }^{25}$ SDF-1 $\alpha$ also secreted by KCs activates the HSCS via CXCR4 on the HSC membrane. ${ }^{26}$ This SDF-1 $\alpha-C X C R 4$ system directly activates HSCS, which transform into myofibroblasts and express CXCR4 on those membranes. ${ }^{26}$ Hong et al. ${ }^{27}$ reported that activation of the CXCR4 receptor of SDF-1 $\alpha$ causes inflammation and fibrogenesis in the liver. Autocrine SDF-1 $\alpha-C X C R 4$ expressed by activated HSCs was enhanced with progression of NASH, because activated HSCS in the NAFLD rodent model not only increased the number of CXCR4 receptors but also enhanced the binding affinity of SDF-1 $\alpha$ CXCR4. ${ }^{28}$ The present study revealed that serum levels of SDF- $1 \alpha$ were statistically higher by grade of fibrosis, and a correlation between serum levels of SDF- $1 \alpha$ and fibrosis was observed $(r=0.649$, $P<0.001)$. Moreover, serum levels of SDF-1 $\alpha$ were statistically higher by grade of steatosis and inflammation.

Serum levels of SCGF- $\beta$ and SCF were measured in the present study because progression of NASH involves proliferation and migration of stem cells and HPCs. ${ }^{8}$ No reports were found regarding serum level of either SCGF- $\beta$ or SCF in NASH patients. Serum levels of SCGF- $\beta$ and SCF appear to be related to inflammation.

Leptin is a well-known cytokine related to obesity by its absence or insufficient signaling; it also reduces development of fibrosis in models of liver injury. ${ }^{29} \mathrm{KCs}$ have been identified as the cellular target of the profibrogenic action of leptin. ${ }^{30}$ The present study showed a statistical correlation between serum levels of leptin and grades of steatosis and inflammation ( $r=0.505$, $P<0.001 ; r=0.483, P<0.002$, respectively). Serum levels of leptin were not higher in the $\mathrm{F} 4$ group even though multiple intracellular signaling pathways in HSCs were reported to be activated by leptin. ${ }^{31}$ However, exposure of rat HSCs to leptin maintained the quiescent state of HSCs by inhibitory activity of the peroxisome proliferator-activated receptor- $\gamma .{ }^{32}$ This result is consistent with our present findings.

Ghrelin is an appetite-stimulating hormone with function opposite to that of leptin. Machado et al. reported that ghrelin seems to be associated with more severe NAFLD. ${ }^{33}$ Another report by Gonciarz et al. showed no significant difference in ghrelin plasma levels in NASH patients treated with melatonin. ${ }^{34}$ Ghrelin is an important cytokine in NASH patients requiring further research.

Patient with NASH are often accompanied by atherosclerosis, diabetes, and cardiovascular disease. ${ }^{4,35}$ The present study demonstrated that $\mathrm{HbA1c}$ and clinical findings of metabolic syndrome as a marker of extrahepatic inflammatory conditions in NASH did not effect on serum levels of MMP-1. The numbers of NASH patients with diabetes or metabolic syndrome, however, were not sufficient to get a final conclusion. Further investigation in large sample study will be needed to clarify whether serum level of MMP-1 and SDF-1 $\alpha$ are useful biomarkers of disease activity and 
disease progression in F1 group of NASH, whether extrahepatic conditions effect on serum levels of MMP-1, and whether pioglitazone treatment results in reduction of MMP-1 levels that parallel to a similar decrease in serum ALT. Belfort et al. ${ }^{36}$ reported significant improvement of steatosis, inflammation and ballooning of hepatocytes in patients treated with pioglitazone by improving insulin resistance. In particular, they reported that the decrease in rate of steatosis was significantly lower in the pioglitazone treatment group compared with the placebo group, and the plasma adiponectin level increased. When pioglitazone was administered for two or more years, Nakayama et al..$^{37}$ reported significant improvement of ALT, total cholesterol, HbA1c and histologically observed improvement of lipid droplets, intravesicular inflammation, and fibrosis. Pioglitazone decreased MMP-1 and increased SDF$1 \alpha$ levels in patients of the F1 group of NASH. These trends were seen only in the F1 group, suggesting that very complex cytokine reactions in this particular stage of the disease lead to improvement or progression of NASH.

Our observation of the dual expression of MMP-1 and OV-6/K19 revealed positive staining of both in HPCs, ductular cells and socalled small hepatocytes, suggesting that the MMP-1-positive HPCs differentiated or transformed into hepatocytes, ductular cells, myofibroblasts and elongated repaired ECs, as described previously. ${ }^{8}$ The mechanism of MMP-1 expression in MCs, KCs and HSCs may involve exposure to exosomes containing miRNA related to the appearance of MMP-1 secreted from MCs. ${ }^{38}$ MMP-1 plays a central role in degrading the extracellular matrix in the recovery phase of experimental liver fibrosis in rats, ${ }^{4,10-13,39}$ but MMP-1 seems to cause dedifferentiation of MMP-1 expressed cells. ${ }^{8}$ MMP-1 is considered to be involved in the progression of NASH pathology. ${ }^{8}$ MMP-1 may play a kick-starter role as a rapid reaction to oxidative stress, i.e., higher levels of MMP-1 contribute to the further progression to NASH. We are currently investigating the mechanism of MMP-1 expression in MCs, KCs and HSCs focusing on excretion of exosomes, including miRNA causing MMP1 expression.

\section{Additional information}

Some of the findings in this manuscript were presented in the poster session at the AASLD Liver Meeting 2014 (Ando W et al. The serum levels of SDF-1 $\alpha$ correlated with the fibrosis and suggested the appearance of hepatic progenitor cells in the advanced stage of NASH, Hepatology 2014;60(Suppl 1):611A).

\section{Ethical approval}

All procedures performed in studies involving human participants are in accordance with the ethical standards of the institutional and/or national research committee and with the 1964 Helsinki Declaration and its later amendments or comparable ethical standards.

\section{Informed consent}

Informed consent was obtained from all participants enrolled in the study.

\section{Authors' contribution}

WA managed this study, measured and analyzed the biomarkers, collected patients' clinical data, and wrote the manuscript. HY, YI and IO recruited patients for the study, collected blood samples, evaluated histological grading or scale of liver tissue taken by needle biopsy, and critically reviewed the manuscript. NT, EY and YS recruited patients, collected blood samples, and evaluated histological grading or scale of liver tissue taken by needle biopsy. $\mathrm{KO}$ critically reviewed the manuscript. MO and $\mathrm{IO}$ developed the research concept and contributed to the design of the study.

\section{Acknowledgments}

The authors thank Mr. Yukinobu Haruyama, Chief of the Clinical Laboratory, International University Hospital, and his staff for their contribution to the project, and Ms. Cecilia Hamagami for assistance in the English revision of the manuscript. The fund by Mr. Takeshi Mori and Mrs. Eiko Mori given to Dr. Okazaki have supported this work.

\section{Conflicts of Interest}

The authors have no conflicts to disclose.

\section{SUPPLEMENTARY MATERIALS}

Supplementary materials are available at Clinical and Molecular Hepatology website (http://www.e-cmh.org).

\section{REFERENCES}

1. Younossi ZM, Blissett D, Blissett R, Henry L, Stepanova M, Younossi 
$Y$, et al. The economic and clinical burden of nonalcoholic fatty liver disease in the United States and Europe. Hepatology 2016;64:15771586.

2. Sakamoto M, Tsujikawa H, Effendi K, Ojima H, Harada K, Zen Y, et al. Pathological findings of nonalcoholic steatohepatitis and nonalcoholic fatty liver disease. Pathol Int 2017;67:1-7.

3. Cohen JC, Horton JD, Hobbs HH. Human fatty liver disease: old questions and new insights. Science 2011;332:1519-1523.

4. Okazaki I, Noro T, Tsutsui N, Yamanouchi E, Kuroda H, Nakano M, et al. Fibrogenesis and carcinogenesis in nonalcoholic steatohepatitis (NASH): involvement of matrix metalloproteinases (MMPs) and tissue inhibitors of metalloproteinase (TIMPs). Cancers (Basel) 2014;6:1220-1255.

5. Moro T, Nakao S, Sumiyoshi $H$, Ishii T, Miyazawa M, Ishii N, et al. A combination of mitochondrial oxidative stress and excess fat/calorie intake accelerates steatohepatitis by enhancing hepatic CC chemokine production in mice. PLoS One 2016;11:e0146592. doi: 10.1371/ journal.pone.0146592. eCollection 2016.

6. Henao-Mejia J, Elinav E, Jin C, Hao L, Mehal WZ, Strowig T, et al. Inflammasome-mediated dysbiosis regulates progression of NAFLD and obesity. Nature 2012;482:179-185.

7. Bullock RE, Zaitoun AM, Aithal GP, Ryder SD, Beckingham IJ, Lobo DN. Association of non-alcoholic steatohepatitis without significant fibrosis with hepatocellular carcinoma. J Hepatol 2004;41:685-686.

8. Yokomori H, Inagaki Y, Ando W, Hara M, Komiyama T, Kojima S, et al. Spatiotemporal expression of matrix metalloproteinase- 1 in progression of nonalcoholic steatohepatitis. J Mod Hum Pathol 2016;1:11-20.

9. Yokomori H, Oda M, Ando W, Inagaki Y, Okazaki I. Hepatic progenitor cell expansion in early-stage nonalcoholic steatohepatitis: evidence from immunohistochemistry and immunoelectron microscopy of matrix metalloproteinase-1. Med Mol Morphol 2017 Jun 2. doi: 10.1007/s00795-017-0162-y. [Epub ahead of print]

10. Okazaki I, Nabeshima K. Introduction: MMPs, ADAMs/ADAMTSs research products to achieve big dream. Anticancer Agents Med Chem 2012;12:688-706.

11. limuro Y, Nishio T, Morimoto T, Nitta T, Stefanovic B, Choi SK, et al. Delivery of matrix metalloproteinase-1 attenuates established liver fibrosis in the rat. Gastroenterology 2003;124:445-458.

12. Siller-López F, Sandoval A, Salgado S, Salazar A, Bueno M, Garcia J, et al. Treatment with human metalloproteinase-8 gene delivery ameliorates experimental rat liver cirrhosis. Gastroenterology 2004;126:1122-1133; discussion 949.

13. Endo H, Niioka M, Sugioka Y, Itoh J, Kameyama K, Okazaki I, et al. Matrix metalloproteinase-13 promotes recovery from experimental liver cirrhosis in rats. Pathobiology 2011;78:239-252.

14. Saunders WB, Bayless KJ, Davis GE. MMP-1 activation by serine proteases and MMP-10 induces human capillary tubular network col- lapse and regression in 3D collagen matrices. J Cell Sci 2005;118(Pt 10):2325-2340.

15. Brunt EM, Janney CG, Di Bisceglie AM, Neuschwander-Tetri BA, Bacon BR. Nonalcoholic steatohepatitis: a proposal for grading and staging the histological lesions. Am J Gastroenterol 1999;94:24672474.

16. Kleiner DE, Brunt EM, Van Natta M, Behling C, Contos MJ, Cummings $\mathrm{OW}$, et al. Design and validation of a histological scoring system for nonalcoholic fatty liver disease. Hepatology 2005;41:13131321.

17. Hoofnagle JH, Van Natta ML, Kleiner DE, Clark JM, Kowdley KV, Loomba $R$, et al. Vitamin $E$ and changes in serum alanine aminotransferase levels in patients with non-alcoholic steatohepatitis. Aliment Pharmacol Ther 2013;38:134-143.

18. Kanda Y. Investigation of the freely available easy-to-use software 'EZR' for medical statistics. Bone Marrow Transplant 2013;48:452458.

19. Heissig B, Hattori $K$, Dias S, Friedrich M, Ferris B, Hackett NR, et al. Recruitment of stem and progenitor cells from the bone marrow niche requires MMP-9 mediated release of kit-ligand. Cell 2002;109:625-637.

20. Miele L, Forgione A, La Torre G, Vero V, Cefalo C, Racco S, et al. Serum levels of hyaluronic acid and tissue metalloproteinase inhibitor-1 combined with age predict the presence of nonalcoholic steatohepatitis in a pilot cohort of subjects with nonalcoholic fatty liver disease. Transl Res 2009;154:194-201.

21. Toyoda H, Kumada T, Kiriyama S, Tanikawa M, Hisanaga Y, Kanamo-


trix metalloproteinase-2 are associated with steatohepatitis in nonalcoholic fatty liver diseases. Biomarkers 2013;18:82-87.

22. Marra F, Tacke F. Roles for chemokines in liver disease. Gastroenterology 2014;147:577-594.e1.

23. Song YS, Joo HW, Park IH, Shen GY, Lee Y, Shin JH, et al. Granulocyte-colony stimulating factor prevents the development of hepatic steatosis in rats. Ann Hepatol 2015;14:243-250.

24. Lei Y, Liu Z, Han Q, Kang W, Zhang L, Lou S. G-CSF enhanced SDF-1 gradient between bone marrow and liver associated with mobilization of peripheral blood CD34+ cells in rats with acute liver failure. Dig Dis Sci 2010;55:285-291.

25. Mendt M, Cardier JE. Stromal-derived factor-1 and its receptor, CXCR4, are constitutively expressed by mouse liver sinusoidal endothelial cells: implications for the regulation of hematopoietic cell migration to the liver during extramedullary hematopoiesis. Stem Cells Dev 2012;21:2142-2151.

26. Furusato $B$, Mohamed $A$, Uhlén $M$, Rhim JS. CXCR4 and cancer. Pathol Int 2010;60:497-505.

27. Hong F, Tuyama A, Lee TF, Loke J, Agarwal R, Cheng X, et al. Hepatic stellate cells express functional CXCR4: role in stromal cell- 
derived factor-1alpha-mediated stellate cell activation. Hepatology 2009:49:2055-2067.

28. Boujedidi H, Robert O, Bignon A, Cassard-Doulcier AM, Renoud ML, Gary-Gouy H, et al. CXCR4 dysfunction in non-alcoholic steatohepatitis in mice and patients. Clin Sci (Lond) 2015;128:257-267.

29. Marra F, Navari N, Vivoli E, Galastri S, Provenzano A. Modulation of liver fibrosis by adipokines. Dig Dis 2011;29:371-376.

30. Ikejima K, Takei Y, Honda H, Hirose M, Yoshikawa M, Zhang YJ, et al. Leptin receptor-mediated signaling regulates hepatic fibrogenesis and remodeling of extracellular matrix in the rat. Gastroenterology 2002;122:1399-1410.

31. De Minicis S, Seki E, Oesterreicher C, Schnabl B, Schwabe RF, Brenner DA. Reduced nicotinamide adenine dinucleotide phosphate oxidase mediates fibrotic and inflammatory effects of leptin on hepatic stellate cells. Hepatology 2008;48:2016-2026.

32. Zhou Y, Jia X, Wang G, Wang X, Liu J. PI-3 K/AKT and ERK signaling pathways mediate leptin-induced inhibition of PPARgamma gene expression in primary rat hepatic stellate cells. Mol Cell Biochem 2009;325:131-139.

33. Machado MV, Coutinho J, Carepa F, Costa A, Proença H, CortezPinto $\mathrm{H}$. How adiponectin, leptin, and ghrelin orchestrate together and correlate with the severity of nonalcoholic fatty liver disease.
Eur J Gastroenterol Hepatol 2012;24:1166-1172.

34. Gonciarz M, Bielański W, Partyka R, Brzozowski T, Konturek PC, Eszyk J, et al. Plasma insulin, leptin, adiponectin, resistin, ghrelin, and melatonin in nonalcoholic steatohepatitis patients treated with melatonin. J Pineal Res 2013;54:154-161.

35. Willner IR, Waters B, Patil SR, Reuben A, Morelli J, Riely CA. Ninety patients with nonalcoholic steatohepatitis: insulin resistance, familial tendency, and severity of disease. Am J Gastroenterol 2001;96:2957-2961.

36. Belfort R, Harrison SA, Brown K, Darland C, Finch J, Hardies J, et al. A placebo-controlled trial of pioglitazone in subjects with nonalcoholic steatohepatitis. N Engl J Med 2006;355:2297-2307.

37. Nakayama H, Iwahasi S, Ojima T, Kusano M, Asano S, Sugai Y. Long term effects of pioglitazone therapy with nonalcoholic steatohepatitis. Kanzo 2009;50:555-564.

38. Colombo M, Raposo G, Théry C. Biogenesis, secretion, and intercellular interactions of exosomes and other extracellular vesicles. Annu Rev Cell Dev Biol 2014;30:255-289.

39. Higashiyama R, Inagaki Y, Hong YY, Kushida M, Nakao S, Niioka M, et al. Bone marrow-derived cells express matrix metalloproteinases and contribute to regression of liver fibrosis in mice. Hepatology 2007;45:213-222. 